\title{
AGMP 2012: Preface
}

\author{
Miroslav Kurě̌
}


AGMP 2012: PREFACE

\author{
MIROSLAV KUREŠ
}

It was in October 2007 that two representatives of the Brno school of differential geometry attended the Algebra, Geometry and Mathematical Physics (AGMP) conference, and I had the honour to be one of them. The venue of the then third year of the conference was Göteborg, Sweden where interesting topics such as deformation theory and quantization, Hopf algebras, quantum algebras, integrable systems, Lie theory and applications, and others appeared. Dubbed Baltic-Nordic Workshop, the conference also served as a meeting point with mathematicians and physicists from areas - somewhat illogically — distant to us. Cooperation was initiated and further annual conference at Tartu, Będlewo, Tjärnö, and Mulhouse were always attended by someone from Brno. This was also reflected in closer personal ties and, as an honour, we could then accept an offer to hold the eighth AGMP conference in Brno made to me and my colleagues, Petr Vašík and Jaroslav Hrdina, by the main organizer Prof. Eugen Paal from Technical University in Tallinn during our stay at Tallinn in 2011. Thus, the basis of an organising committee was formed.

We believe that trying to organize this year's conference with a touch of originality was a step in the right direction. The idea of our specific contribution to the conference was twofold. First to introduce to it Czech specialists in differential geometry, a field with a living tradition in the Czech Republic. Thus, thanks our obliging more noted colleagues, new names appeared at the conference such as Ivan Kolár̆, Josef Mikeš, Martin Markl, Demeter Krupka, Olga Rossi, and many other colleagues from abroad with long cooperation with Czech universities. Second, we wanted to enrich the conference thematically, too: we did this by increasing emphasis on jet spaces, Weil bundles, new geometric views at infinitesimals, quantum theory of strings, kinematic theory of defective crystals, and other topics. 
The participants might want to recall — and other readers perhaps to learn about — the conference plenary lectures:

$\diamond$ Paolo Giordano: Infinitesimals without logic

$\diamond$ Natalia Iyudu: Golod-Shafarevich algebras, NCCI and RCI

$\diamond$ Ivan Kolár: On the interrelations between jet spaces and Weil bundles

$\diamond$ Hirokazu Nishimura: Axiomatic differential geometry — towards model categories of differential geometry

$\diamond$ Maria Clara Nucci: Symmetries for thought

$\diamond$ Gareth Parry: Geometrical issues in the continuum mechanics of defective solid crystals

$\diamond$ Ivo Sachs: On homotopy algebras and quantum string field theory

$\diamond$ Sergey Stepanov: Tachibana numbers

$\diamond$ Karl Strambach: Geodesics and foundation of geometry

Let us also list the specialised sections with parallel programmes:

$\diamond$ Deformation theory and quantization

$\diamond$ Geometry of manifolds with connection

$\diamond$ Geometry in mechanics and thermodynamics

$\diamond$ Jordan algebras and applications

$\diamond$ Jet theory and Weil bundles

$\diamond$ Noncommutative algebra and geometry

$\diamond$ Operads, Feynman transform and string field theory

$\diamond$ Symmetry and integrability Variational geometry

The conference was held from 12th to 14th September 2012 at Brno University of Technology. The organizing committee members included M. Kureš (Chair), J. Hrdina, E. Paal, P. Sehnalová, A. Stolin, P. Vašík, J. Zatočilová. Much support for the organizers came from Miroslav Doupovec, the Dean of the BUT Faculty of Mechanical Engineering, and Josef Šlapal, the Director of the Institute of Mathematics of the faculty. We would also like to express our gratitude to the city of Brno and the South Moravian Region for their help, too. Already during the conference, positive reactions could be observed to the somewhat non-traditional mix of the traditional topics of the AGMP series with those presented by the Czech participants: more discussions took place in the corridors than usual at events of this type with the organizers receiving positive responses to the programme structure. The total conference attendance was 111 participants from 28 countries. Knowing that it is only the time that will show whether the contacts initiated are going to last and result in valuable research cooperation, we still had an impression that the circumstances were favourable. Speaking about the accompanying events, a walk in downtown Brno should be mentioned even if spoiled by the rain. Another event of the social programme was a conference dinner at the U královny Elišky wine bar with a cimbalom band. We will be glad if the participants feel that the positive memories of the conference prevail hoping that any inconveniences will be forgiven and forgotten. 
This extraordinary issue of Miskolc Mathematical Notes is a selection of the papers submitted based on careful reviews. The issue editorial board worked efficiently and it is my pleasant duty to thank all its members as listed in the imprint.

The order of papers in this issue is according to the thematic topic and is as follows.

I. Main Contributions — Plenary Lectures ............. pp. 407-486

II. Jet Theory, Weil Bundles, Variational Geometry .............pp. 487-555

III. Riemannian Geometry, Geometry of Manifolds with Connection ........................... pp. 557-636

IV. Symmetry and Integrability, Geometry of Mechanics

and Thermodynamics ......................... 637-711

V. Noncommutative Algebra and Geometry ..............pp. 713-727

ISSUE EDITOR-IN-CHIEF:

Miroslav Kurěs, Brno, CZ

Editorial Vice-Head ANd Associate AdViser:

Eugen Paal, Tallinn, EE

EDITORS:

Roman Cherniha, Kyiv, UA

Jan Kurek, Lublin, PL

Martin Markl, Praha, CZ

Josef Mikeš, Olomouc, CZ

Gareth Parry, Nottingham, UK

Samuli Piipponen, Joensuu, FI

Sergey Stepanov, Moscow, RU

Alena Vanžurová, Olomouc, CZ

TeCHNICAL EDITOR:

Petr Vašik, Brno, CZ 